\title{
Animal analogies for developing design thinking
}

\author{
C. Dowlen \\ London South Bank University
}

\begin{abstract}
The paper covers the development of a project aimed at first year design students starting out at university. This consists of a series of creative design techniques wrapped up in a managed project to design an animal. These techniques range from conventional processes such as specification writing and model making through to more off-the-wall techniques such as forced serendipity and genetic breeding processes. Students are also introduced to developmental processes such as structural design and systems design through the project. It is hoped to develop the project into an interactive tool for the development of creativity using the animal design project as an illustrative vehicle for the techniques.

Keywords: creativity, animals, design methods, design projects, natural analogies, design education.
\end{abstract}

\section{Introduction}

This project started out as a method of getting students on product design courses to think creatively from the start of their courses. The premise was that students need to be able not just to understand how the business of creativity works, but also need to put it into practice. This needed a vehicle for creative development skills; what was developed was the Design an Animal project. It was first used a decade ago and has been refined and developed, but the essential features have not changed significantly. It was recorded in a paper presented at ICED'05. This paper looks in more detail at the specific exercises involved in the project and the connections between animals, creativity and methods. 


\section{Invented animals}

God... invented the giraffe, the elephant, the cat... He has no real style. He just goes on trying things.

Pablo Picasso

Invented animals are all around us. Not in the theological sense, perhaps, but those invented by humans. They may have started with strange noises round a campfire with werewolves, leviathan, behomoth and the rest of the gang. Or with the Minotaur, centaurs, phoenix, unicorns, griffins, dragons and the like. They have continued with other fictional creatures such as hobbits, orcs, Gollum, trolls: moomins, hemulens, hattifatteners, and fillyjonks: gruffaloes, wombles, and clangers. Even when we make furry, cuddly toy models or write stories about of what animals they seldom resemble their natural counterparts. Winnie the Pooh - of course, such a lovable bear - has little resemblance to a real bear other than liking honey and being approximately the same shape. Real bears don't have that sort of relationship with rabbits and piglets. Stuffed toys of elephants, elks and echidnas are different from the real thing!

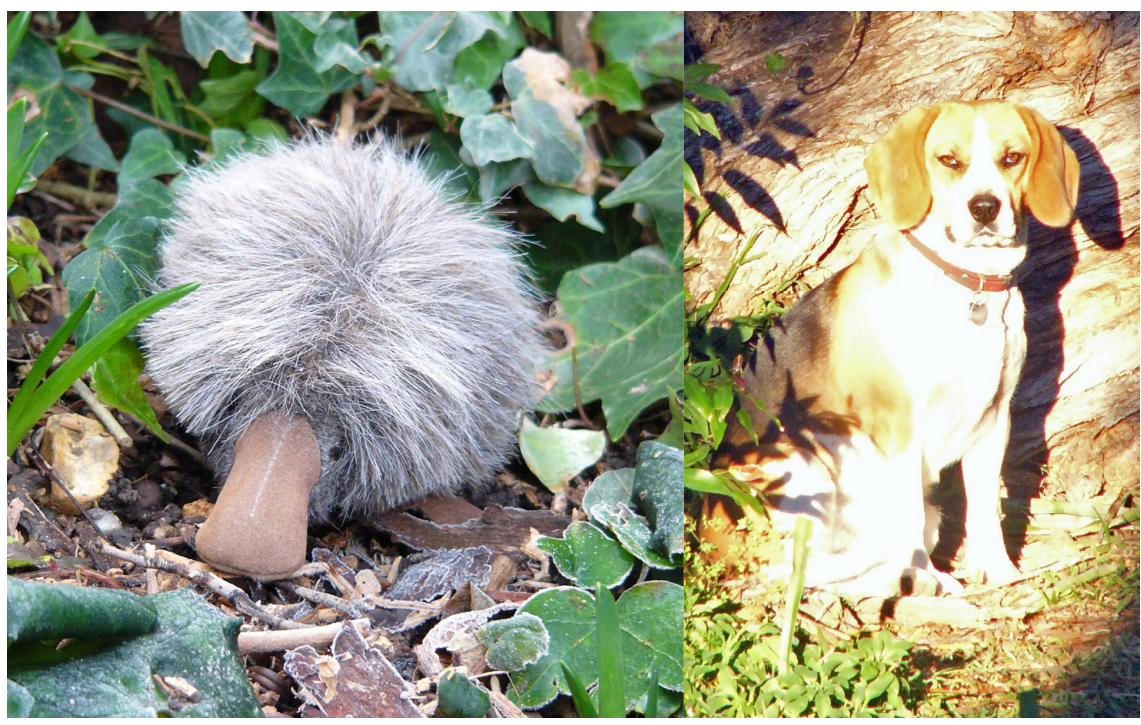

Figure 1: $\quad$ A toy echidna and a real Beagle.

And if you invent stories about them, their characters would be totally different from the real thing. Snoopy - well known as a beagle - is not a real beagle (although this one might still sit on the top of her doghouse). 


\section{Creativity}

Dempsey has a view of creativity that it is inherent in some people - and seemingly not in others:

Creativity is a magical thing that you are born with. It presents itself early and like a virus is unstoppable.

It inhabits the kids who daydream and are good at drawing, but not much else. If I knew where it came from, I would bottle it up and make a fortune.

Michael Dempsey

Robinson reckons that it is something that needs to be developed in schools and universities (but isn't) and is a general skill that should be developed:

Employers are complaining that academic programmes from schools to universities simply don't teach what people now need to know and be able to do. They want people who can think intuitively, who are imaginative and innovative, who can communicate well, work in teams and are flexible, adaptable and self-confident

Robinson

Sternberg collected essays that explored the nature of creativity. These investigated the role of the environment, the role of the individual, and the role of the individual-environment reaction. Creativity, he concludes, has many natures, and these are distinctive. He uses a food analogy to describe the variations, calling some milk, meat, bagels and so on (the final page of the summing up at the end).

\subsection{Developing creativity}

More practically, Petty has a useful little book on creativity - How to be better at... creativity He doesn't try to define creativity. He describes rather than defines it. He investigates different aspects of the process by which the creative initiative becomes embodied in an output. He outlines a combination of six processes that take place, in any order, during this process. These phases are remembered using the ICEDIP mnemonic: Inspiration, Clarification, Evaluation, Distillation, Incubation and Perspiration. Other books take a similar line. Alex Osborn's Applied Imagination was perhaps one of the first to take this approach, but that has been followed up with books such as Roger von Oech's $A$ Whack on the Side of the Head, full of a set of special, illogical methods for the generation of creative ideas. Other texts just provide inspiration for illogicality, such as Alan Fletcher's The Art of Looking Sideways, full of quotations, some of which make sense and others which are totally off the wall.

\subsection{When to develop creativity}

In university design courses creativity should be developed from the day the students appear, and its development should carry on to the end of the course. 


\section{The specific exercise}

This exercise was part of the students' initial design project experience on Product Design degrees.

Students carried out a range of techniques to develop creativity around the topic of designing an animal. How the idea of creating animals arrived is hidden somewhere in the mists of time, although it has proved a worthy vehicle for the exercise. Some of the techniques work particularly well with that as a topic, whilst some work as well with animals as with other topics. Some techniques are group ones: others are individual. Some are designed to generate ideas; others to develop them and to put flesh onto them to arrive at functional solutions. Some are conventional processes written in texts: others those that seem to fit with the topic at hand but could be utilised on many other design tasks. Using animals as the project provided a useful metaphor so that purposeful but slightly off-thewall techniques could be integrated, tried and tested in a manner that might have seemed irrelevant otherwise. The managed project approach guided students to carry out specific procedures rather than leaving them to develop their own thinking processes.

\subsection{Particular techniques}

These were as follows: animal consequences (or a modification of potpourri), brainstorming, forced serendipity, emotional responses, forced serendipity, use of existing ideas, selection of wild ideas, morphological charts, affinity diagrams, combinatory processes, NAF, criteria selection, systems diagrams, genetic processes, imaginative composition, personal analogy, SWOT, threedimensionality, structural design, embodiment design, specification writing, revision of drafts, model making, packaging / display.

Firstly, students are put into groups. Whilst this can be done in many ways, a simplistic approach is taken using each student's favourite animal as an indicator. When this was done first the groups were mixed ones so that cats, dogs, chimpanzees and creepy-crawlies were spread around the class. Later, better results were obtained all round by making groups with similar animals.

\subsection{Ideation techniques}

\subsubsection{Animal consequences}

An introductory game to get the students thinking laterally and to develop group interaction. The process is a children's game played in a group. Each person starts with a sheet of paper. Eventually a complete animal will be drawn by each person drawing bits of the animal in turn. The results are not predictable: students find the group design effort greater than the individual one - they see that interactions between the design team lead to mixed output and see something of the need to look for serendipity within the creative process. 


\subsubsection{Brainstorming}

Once these initial drawings have been produced, the next task, still in groups, is to have a formal brainstorming session. The term has been developed from its coining by Osborn and some formality of the framework has been lost so it simply means getting ideas. It needs to be recaptured and the structure put back in. It is a group process to generate as many ideas as possible in the least possible time. The use of the animal project allows students to be a little removed from reality and so the process can build on the improbability of the possible outcomes.

\subsubsection{Forced serendipity}

Otherwise known Random Input. The process is carried out using a dictionary to find a random word and students are told to find twenty animal ideas connected with that word. For instance, the random word may be hexavalent. This is not easy to connect with animals - although an immediate connection is that the animals have to connect in groups of six. Or do they have six legs? Or six ways of having sex? Or that they need to have a relationship with six of their kind in order to be happy? And so on. That was only four ideas. Idea generation moves into a different plane as the input has come from outside the group. The character is different from tutor input which focuses more on how students were thinking instead of coming from an unexpected and perverse angle.

\subsubsection{Selection of wild ideas}

The group selects the craziest ideas and uses these to build on to get several others. It is a standard addition to a brainstorming session and one that is particularly useful in the context of developing novelty.

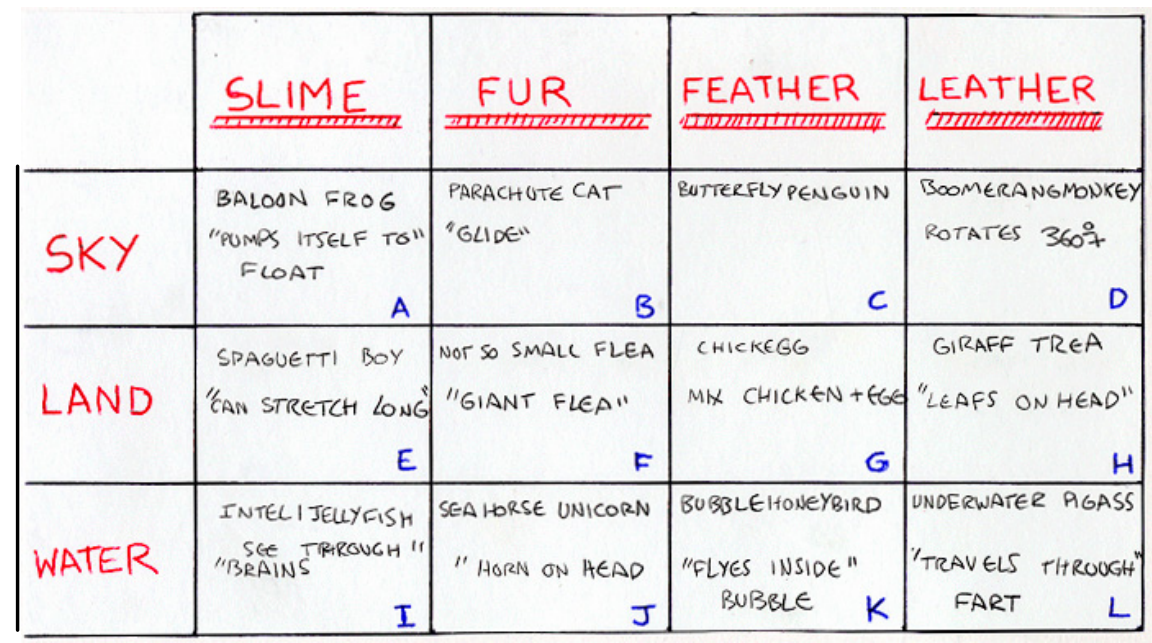

Figure 2: A modification of a morphological chart. 


\subsubsection{Morphological charts}

A standard technique that design students need to be able to use is the morphological chart. Students are asked to produce one of these individually after the group session and to bring the results to the group. The process is explained in Otto and Wood's book Product Design, and in Jones' Design Methods, who refers back to Zwicky. This method is one of the quickest at producing huge quantities of ideas in a limited amount of time: typically there will be millions from a single chart, although the example in Jones only produces 160 ideas and that in Otto and Wood only 65,536 (but note that this is on a single page in the book). Students sometimes misinterpret the concept and produce variations on the morphological chart such as figure 2.

\subsubsection{Use of existing ideas}

In practice, design projects utilise existing ideas to a great extent. This part of the exercise is given as homework. Students find pictures of animals that they respond to emotionally. This can be positive or one of revulsion. It's a useful tool for students to discover the limits of what they will or won't work on. These existing animals are allowed to come into the mix of animals.

\subsubsection{Review of ideas}

It is important that during the gaps between classes students keep a review process going. Students transfer the animal ideas that they have to sheets of A5 paper, one to a sheet, ready for the next part of the process.
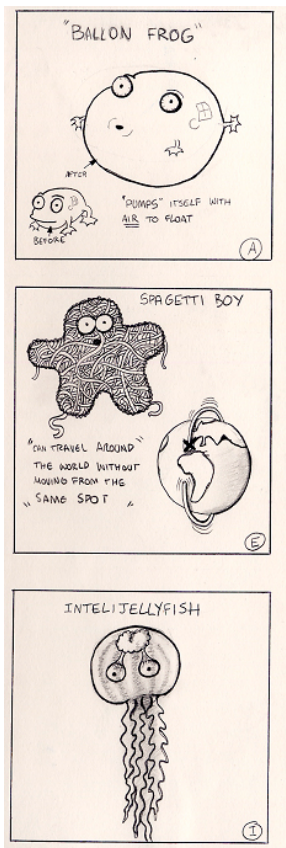
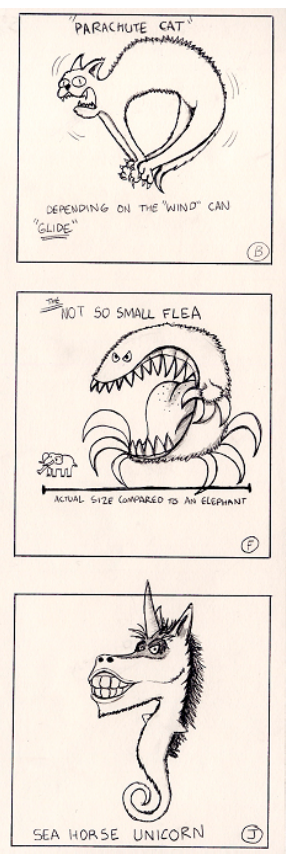
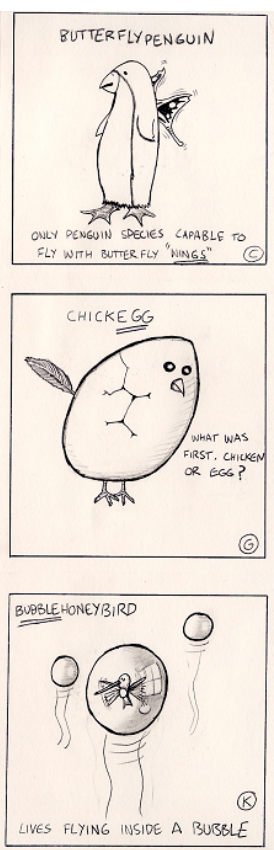
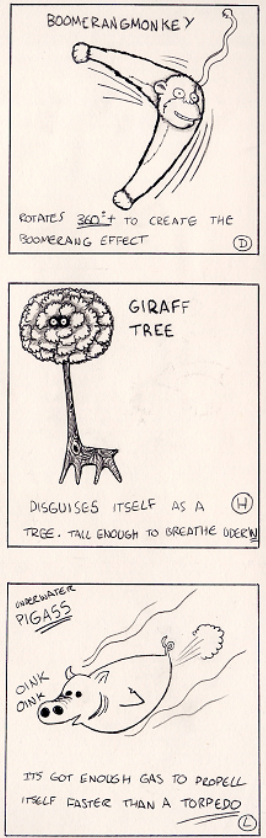

Figure 3: A selection of animal ideas. 


\subsubsection{Affinity diagrams}

Students come with a pile of sheets, each with a different animal idea. They pin them onto a notice board. Then they look at the arrangement of sheets and restructure it, silently, so that it makes sense. Once no further movements take place categories are invented for each cluster.

\subsubsection{The unethical process of stealing ideas}

Students raid the other groups' boards for ideas. Sharing ideas increases the overall quality and builds on the good ones. Students gain judgement by selecting as many useful ideas as possible, and see the currency and worth of their own ideas compared with those of others.

\subsection{Selection techniques}

\subsubsection{NAF}

At this point students are overwhelmed with the quantity of ideas. This is deliberate: it is well known that the more ideas there are, the better the quality of those ideas. Quantity breeds quality. Or, as Petty reports:

Many people wonder where creative people find their good

ideas. The answer is, in among a huge pile of bad ones., p15.

NAF is a quick process for sorting out ideas. It uses three categories: N, A and F. Or Novelty, Attractiveness and Functional. Each group selects ten ideas; five novel, three attractive and two functional ones.

\subsubsection{Selection criteria}

After students have used NAF, general selection criteria are introduced, explaining how product designers would typically use them. It is difficult to determine what criteria might be used to select suitable animals- there don't appear to be customers in the accepted sense of the word.

\subsubsection{Genetic processes}

These are taken loosely in this project. No attempt is made to describe genetic algorithms. Students are introduced to the crazy idea that mixed, confusing animals can breed with each other. Students have to select animals from as large a gene pool as possible and breed them promiscuously. This is a powerful design method - and very effective when using animals. Once a student had been deciding that he was going to use a vampire - only he couldn't spell, so it came out vimpire. This neatly threw a mutation into the system.

\subsection{Developmental techniques}

Then students revisit the selection processes and to continue the development with a single animal idea each. Processes become developmental and there is more energy tied up in the individual creature. 


\subsubsection{Imaginative composition}

Literary processes are used to develop aspects of the animal's lives. Students describe a day in the life of the animal. How does it sleep? Where does it find food? How does it eat it? What does it breathe? When does it contact others of the species? What do they do together? How social are they? How do they mate? What makes a good day? And so on.

\subsubsection{Personal analogy}

This takes imaginative composition further, asking students to describe how it actually feels to become that animal. What sort of emotions does it have? What are its senses like? How does it know about its surroundings? How does it think? Sometimes it's about students putting forward fantasies, but more often they become more involved in improving the development of the creature.

\subsubsection{Three-dimensionality}

The scene shifts from ill-defined ideas to adding flesh onto the bones. They work out how the physical animal goes together and how to present the results of their thinking. The animal has to be three dimensional, and they model it.

\subsubsection{Embodiment design}

This is about putting flesh onto the model. In this phase students are expected to work out physical sizes, loads, weights and so on.

\subsubsection{Structural design}

Firstly, they need to work out what sort of structure takes loads. Natural structures have several forms: chassis-type structures like skeletons, exoskeletons from insects or system structures like plants. There are also structures such as those that are largely supported by the buoyant sea - like jellyfish - and land animals like slugs and worms. How does the animal move? How many legs are on the ground at any one time in order to support the weight?

\subsubsection{Systems design}

How does the animal system work? What happens to food? Where do waste products go? Does it have a circulatory system such as blood? Does it breathe? What happens to matter and energy in the animal? What about controls and feedback systems for nerves? Where do the commands come from? Is there a single command position such as a brain or is there a distributed system?

\subsection{Techniques involved with the deliverable - the model etc}

Students are now told they need to produce a model and associated scenery to demonstrate their animal design.

\subsubsection{Specification writing}

They have to write a specification for the model they are going to make - not for the animal itself, but for it as if the representative model or animal toy. 
Is it full-size or larger or smaller? What facilities have to be used to manufacture it? What toy regulations need to be satisfied? And so on.

\subsubsection{Revision of drafts}

A continuing process but one that students have difficulty with. Getting them to finish a project early to revise it is fraught with difficulty. Revisiting drafts, making multiple prototypes and modifying final drafts is an important design processes.

\subsubsection{Model making and Scene setting}

The embodiment becomes more concrete. Although the project is not covering these areas substantially, it is incomplete without producing some sort of realisation. The scene setting was a small environmental scenario illustrating the animal in its habitat or forming packaging and advertising.

\subsection{Project results}

Figure 4 shows a selection of animals produced over the years.

It can be seen that students build ideas on what they have known before and skills on the skill base they have. But some animals are totally different from anything students have known before - such as the String Glob that had more in common with spaghetti than with a vertebrate.

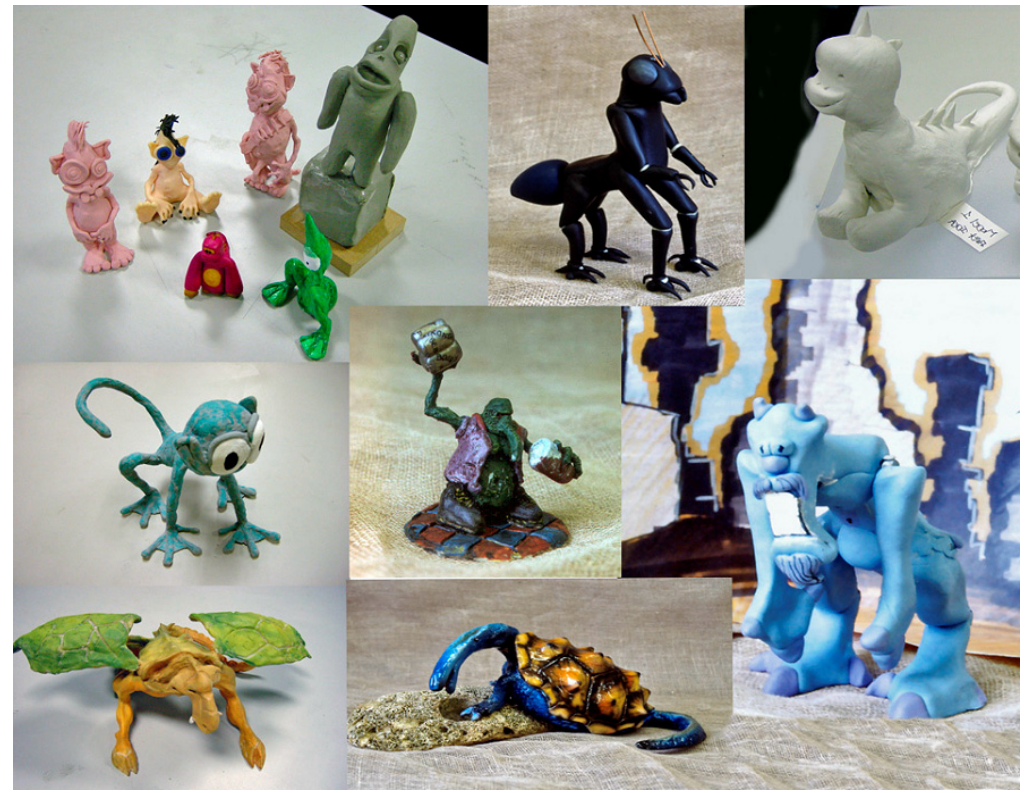

Figure 4: A selection of animal designs created over the years. 
Do students show evidence of developing creativity? Students on the London South Bank courses are creative and obtain employment where creativity is important. Whether this project provides them with creativity tools is harder to quantify. It is clear is that students do not associate the project with a series of creative methods. It seems to be part of the 'mush' of projects that they carry out when they started rather than a discernable toolkit of techniques.

\section{The way forward}

The project has moved on to the next stage. Whilst providing a hands-on toolkit of techniques for first year students is still deemed to be a Good Thing, their forgetting how to use them in the later parts of their courses is not so good. The approach is to embed the processes in a software package for any level of the course to guide them through techniques, applying them to the design of animals as illustrative of how they might be used.

\section{References}

[1] Dowlen, C., Design an animal. Analogies for the development of creativity, International Conference on Engineering Design, The Design Society: Melbourne, 2005.

[2] Dempsey, M., Creative Accounts. In Creative Survey, Design Week, November 2002

[3] Robinson, K., Out of our minds, Capstone: Oxford, 2001.

[4] Sternberg, R. J., The Nature of Creativity: Contemporary Psychological Perspectives, Cambridge University Press: Cambridge, 1988.

[5] Petty, G., How to be Better at ... Creativity, Kogan Page: London, 1997.

[6] Osborn, A. F., Applied Imagination, Scribner: New York, 1953.

[7] Von Oech, R., A Whack on the Side of the Head, Thorsons: London, 1990.

[8] Fletcher, A., The Art of Looking Sideways, Phaidon: London, 2001.

[9] Belbin, R. M., Management Teams: how they succeed or fail,

[10] Levin, P., Successful Teamwork!, Open University Press: Maidenhead, 2005.

[11] Otto, K. and Wood, K., Product Design: Techniques in Reverse Engineering and New Product Development, Prentice Hall: 2001.

[12] Jones, J. C., Design Methods: Seeds of Human Futures, Van Nostrand Reinhold: 1992.

[13] Zwicky, F., The Morphological Method of Analysis and Construction, Courant, Anniversary Volume, 1948 